\title{
Maximum Power Point Tracking of DFIG with DC-Based Converter System Using Coordinated Feedback Linearization Control
}

\author{
Yuliang Sun, ${ }^{1,2}$ Shaomin Yan, ${ }^{1}$ Bin Cai, ${ }^{1}$ and Yuqiang Wu $\mathbb{D}^{1}$ \\ ${ }^{1}$ School of Engineering, Qufu Normal University, Rizhao, China \\ ${ }^{2}$ Shandong Water Conservancy Vocational College, Rizhao, China \\ Correspondence should be addressed to Yuqiang Wu; yu_qiang_wu@126.com
}

Received 28 August 2018; Accepted 22 October 2018; Published 11 November 2018

Guest Editor: Weihai Zhang

Copyright (C) 2018 Yuliang Sun et al. This is an open access article distributed under the Creative Commons Attribution License, which permits unrestricted use, distribution, and reproduction in any medium, provided the original work is properly cited.

\begin{abstract}
This paper presents a coordinated feedback linearization strategy (CFLS) for DC-based doubly-fed induction generator (DFIG) system to track the maximum power point. The stator and rotor of DFIG are connected to DC grid directly by two voltage source converters. Compared with a traditional DFIG system, the DC-based DFIG system has more system inputs and coupling, which increases the difficulty of vector control strategy. Accordingly, CFLS is proposed to make DFIG operate at the maximum power point (MPP), and two aspects are improved: first a single-loop control is adopted to make DFIG operate steady and accurate under coordinated the control of RSC and SSC. Second system control laws are obtained by the feedback linearization strategy that achieves DC-based DFIG system decoupling fully during the MPPT and system control. Simulations are carried out the comparison between CFLS and conventional vector control (VC), and it shows that the control performance of CFLS is superior.
\end{abstract}

\section{Introduction}

In recent years, the technology of wind power generation has developed rapidly, due to its freely available and renewable resource. Variable speed constant frequency doubly fed induction generator (DFIG) is often selected in wind power generation [1]. Compared with the traditional AC transmission, the DC transmission is more economical and stable for the long distance high voltage transmission [2]. The traditional DFIG stator windings are connected to an AC grid by transformer, and the rotor windings is connected to the AC grid by back to back converters. Therefore, the traditional DFIG is used into the DC grid and additional converter will be needed, which is bound to increase the cost [3].

Accordingly, the new converter system is adopted for DFIG in DC grid. A diode-based stator converter interfaces a DFIG with a DC grid, which has the advantages of low cost and simple structure [4-7]. But harmonic may reach from $5.97 \%$ to $11.66 \%$ [8]. An IGBT-based converters system consisting of a rotor side converter (RSC) and a stator side converter (SSC) connects rotor and stator with DC grid, respectively [9-13]. This structure has the advantages that it can reduce the current harmonic effectively and regulate the stator flux and current flexibly according to the needs of the system, not limited to AC grid.

However, the above improved structure results in that the state variables and the system outputs of DFIG with DC-based converters system are twice that of the traditional system, which greatly increases the complexity and coupling of the system and also increases the control difficulty of the system. Therefore, the traditional vector control (VC), which is based on approximate linear model, is difficult to achieve the global optimal control requirements of the new system [14]. Reference [9] adopts indirect air gap flux linkage orientation strategy to control DFIG in a DC grid, but air gap flux linkage is not suitable for measurement. Model predictive control for DFIG in a DC grid is adopted by [13], which requires high precision of system model.

Nowadays, Feedback linearization control (FLC) has been widely used in power electronics and power systems [1521]. It adopts a dual-loop control strategy of FLC and PI to control DFIG in an AC grid in [22]. The advantage of 


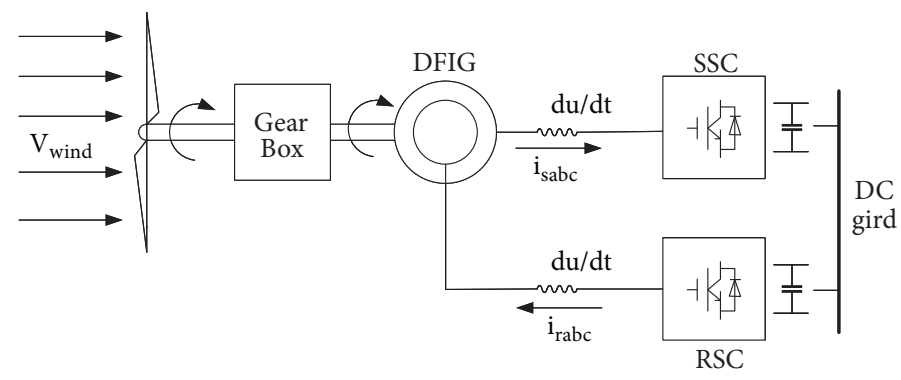

FIGURE 1: DFIG with its DC-based converter system in a DC grid.

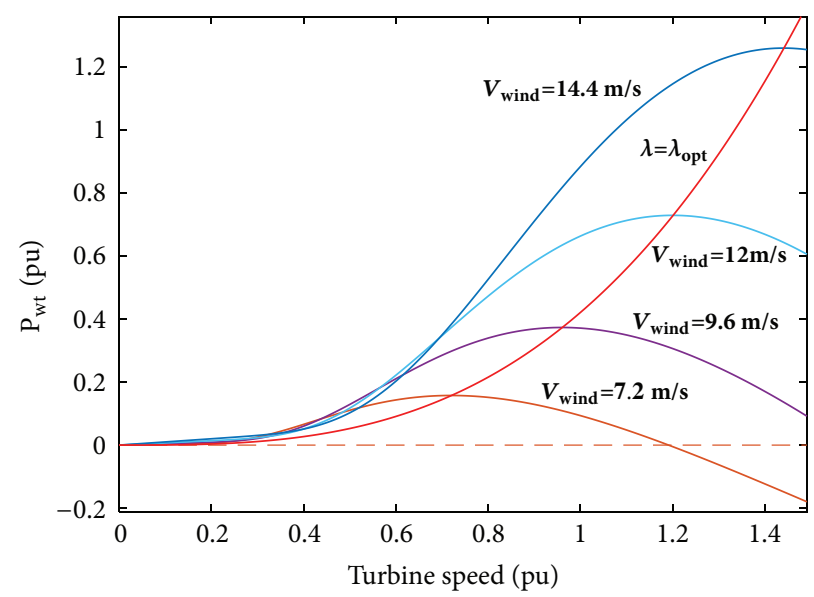

FIGURE 2: The output mechanical power, optimal power, and rotor speed.

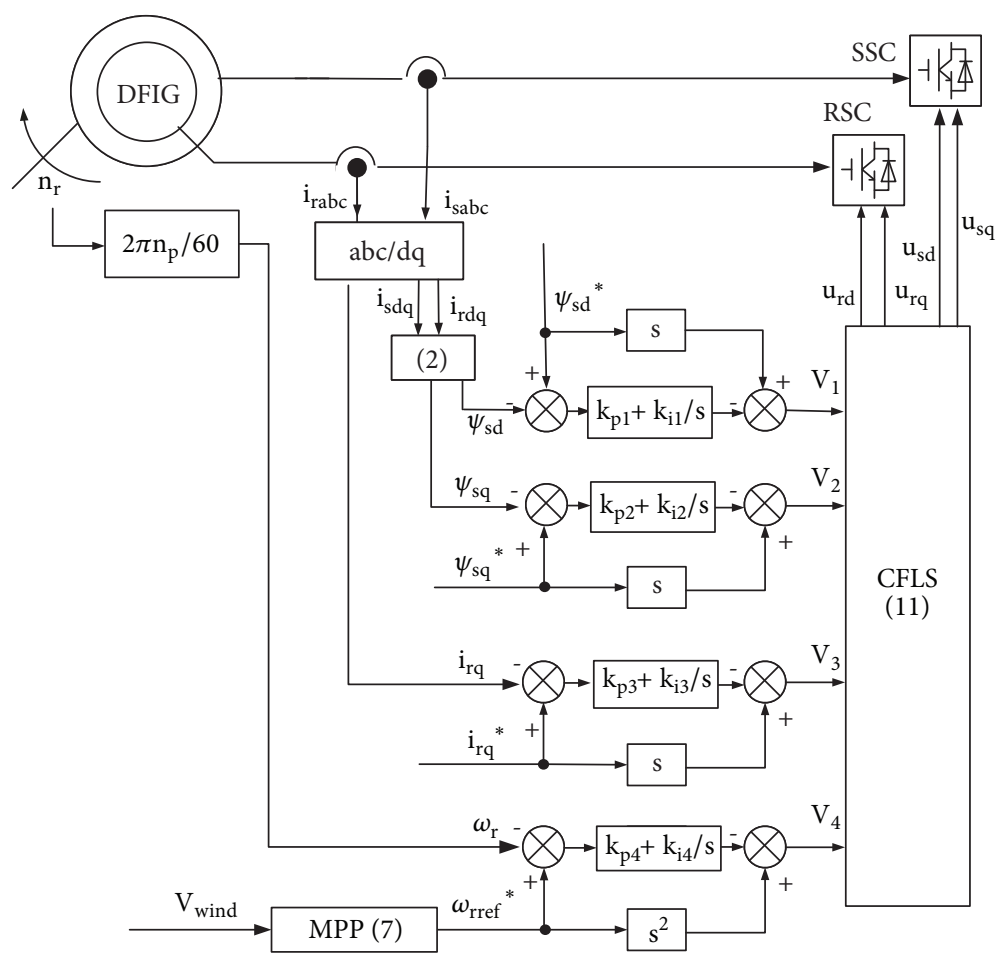

FIgURE 3: Control scheme for RSC and SSC. 

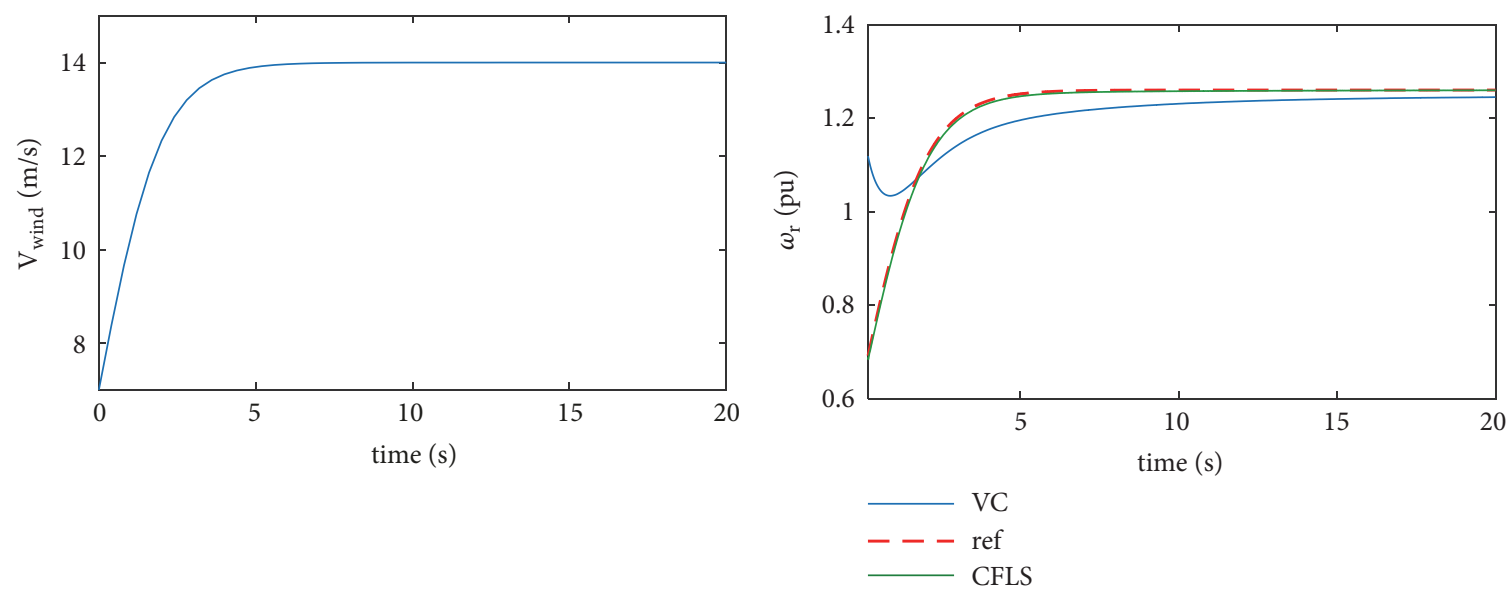

(a)

(b)
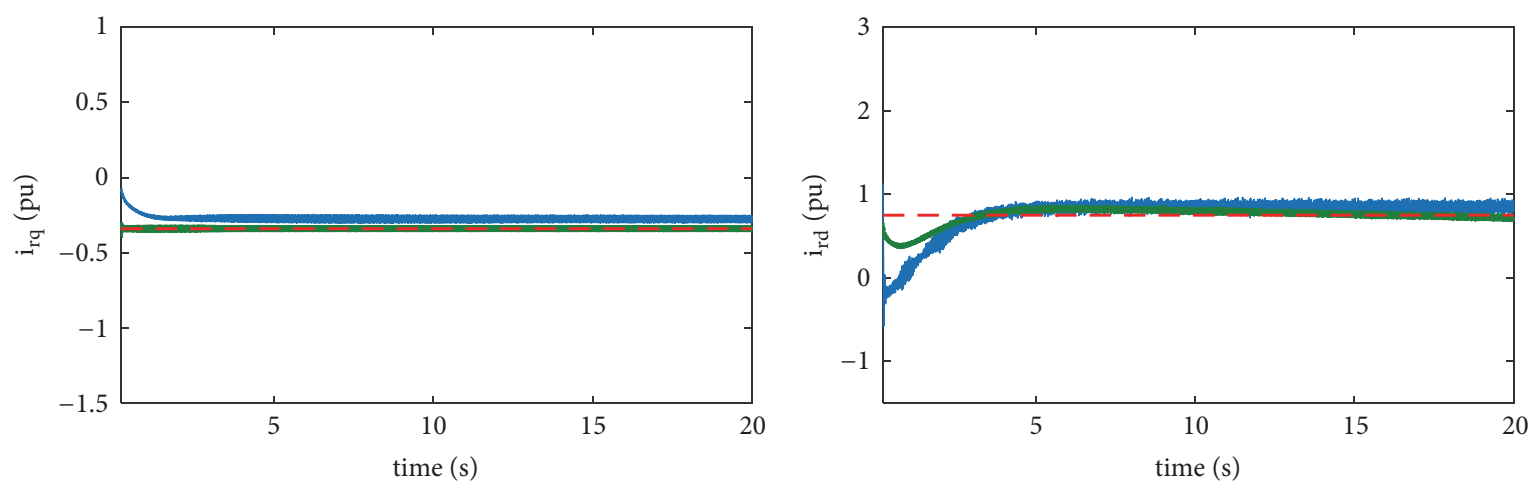

VC

$\mathrm{VC}$

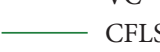

CFLS

--- ref

(c)

(d)
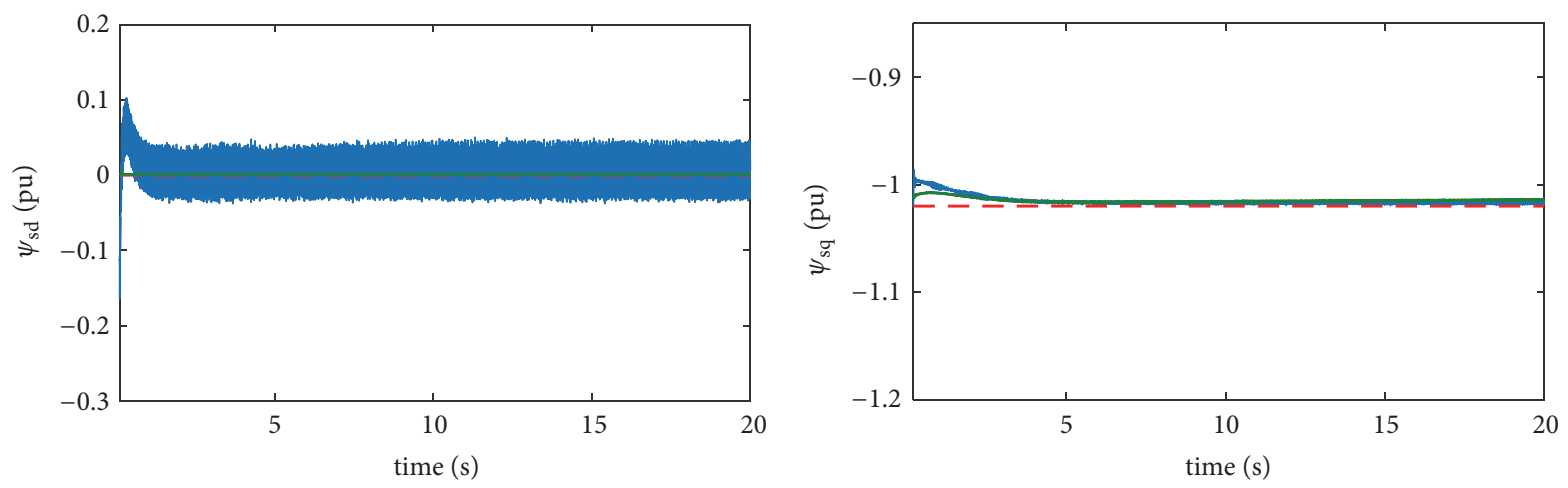

$-\mathrm{VC}$
--- ref
- CFIS

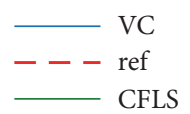

(e)

(f)

FIGURE 4: Performance response to the ramp-change wind speed. 


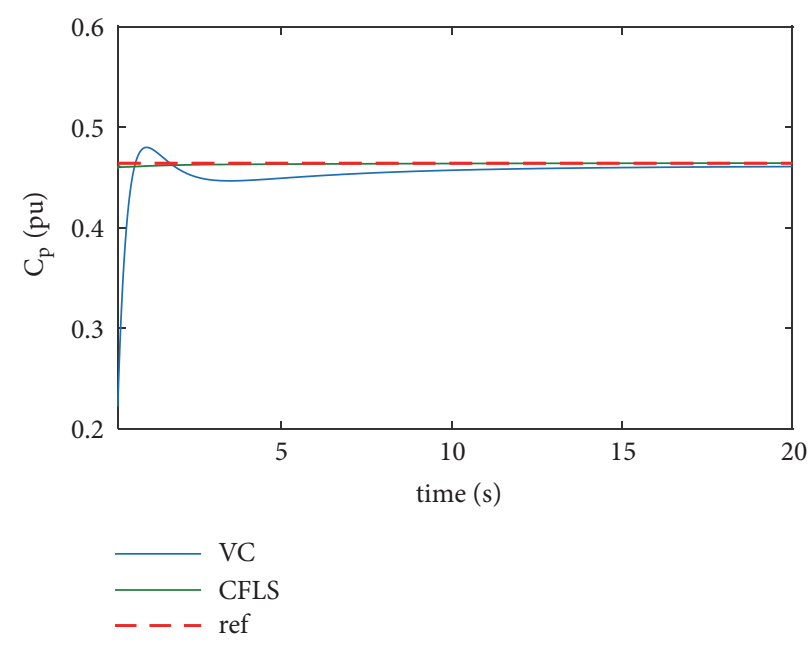

FIGURE 5: $C_{p}$ at the ramp-change wind speed.

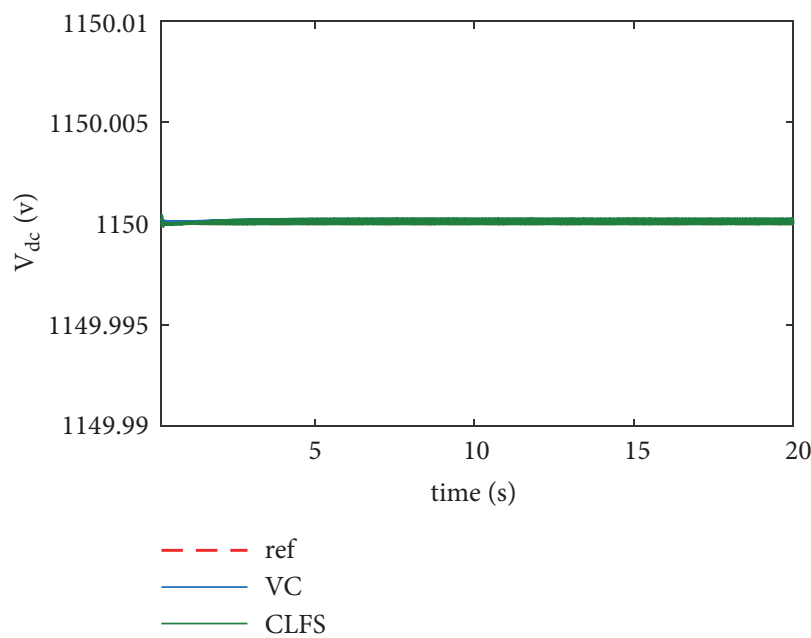

FIGURE 6: $V_{d c}$ at the ramp-change wind speed.

this method is simple to calculate, but the disadvantage is that could not achieve full system decoupling. Article [23] adopts rotor speed and stator reactive power of DFIG in an AC grid as state variables for FLC, which computationally complex and does not select direct system parameters to controller which affects control accuracy [24].

This paper designs a CFLS for DC-based DFIG to achieve maximum power point tracking (MPPT). This control strategy employs stator flux, rotor speed, and rotor current as system inputs, applies FLC to make up a single-loop control, and achieves complete decoupling of the system, which attains coordinated optimal control performance between the SSC and the RSC. This proposed control strategy has better control accuracy and tracking speed than the traditional VC strategy.

The paper is organized as follows. In Section 2, the model of DFIG based on DC grid is introduced. In Section 3, the maximum wind power is achieved by designing CFLS.
In Section 4, simulation studies are evaluate the control performance of the proposed control strategy on a DCbased DFIG system. Finally there is conclusion of this paper.

\section{Modeling of DFIG System}

2.1. System Configuration. DFIG with its DC-based converters system in a DC grid is shown in Figure 1 [12]. The stator and the rotor of DFIG are connected to a DC grid through SSC and RSC. The stator voltage and frequency are completely unrestricted by the power grid. SSC can adjust stator voltage and frequency to control stator current and compensate stator reactive power. RSC can adjust rotor voltage to control rotor flux. The du/dt filter inductors are connected to stator and rotor, respectively, to prevent sharp voltage caused by converters and smooth currents. 


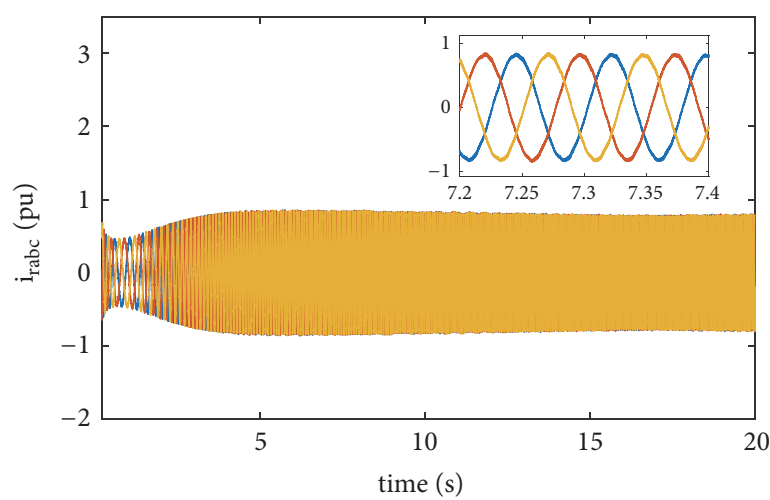

(a) Rotor currents $i_{r a b c}$ under CFLS

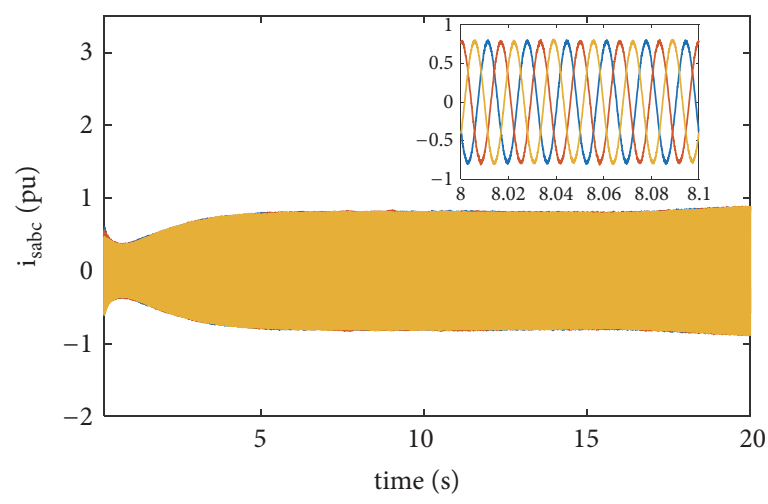

(c) Stator currents $i_{\text {sabc }}$ under CFLS

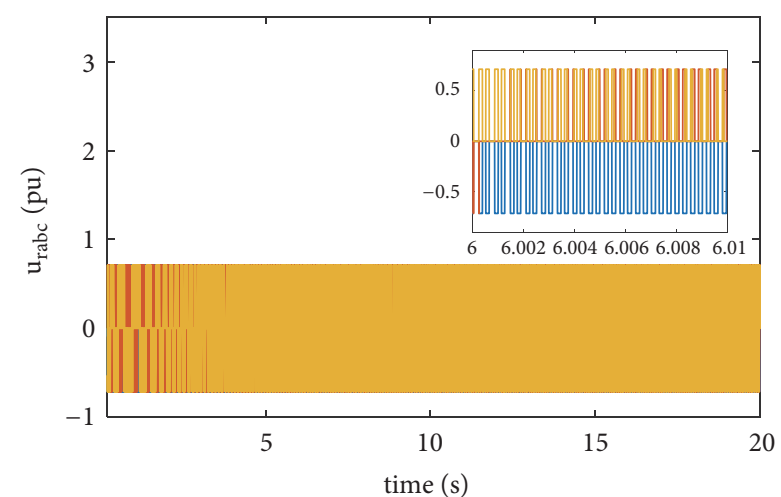

(b) Rotor voltages $u_{r a b c}$ under CFLS

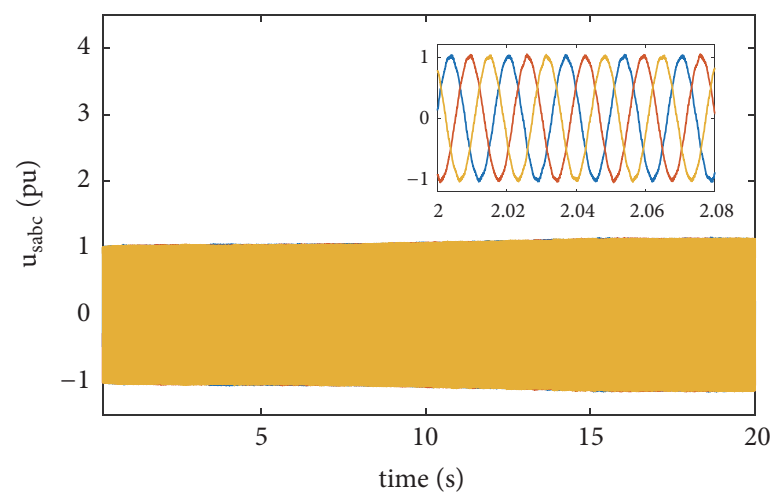

(d) Stator voltages $u_{s a b c}$ under CFLS

Figure 7: Performance response to the ramp-change wind speed.

2.2. DFIG Model Description. In this paper, DFIG model is adopted according to the motor direction in a d-q synchronous frame that can be expressed as $[24,25]$

$$
\begin{aligned}
u_{s d} & =\frac{\mathrm{d} \psi_{s d}}{\mathrm{~d} t}-\omega_{1} \psi_{s q}+R_{s} i_{s d} \\
u_{s q} & =\frac{\mathrm{d} \psi_{s q}}{\mathrm{~d} t}+\omega_{1} \psi_{s d}+R_{s} i_{s q} \\
u_{r d} & =\frac{\mathrm{d} \psi_{r d}}{\mathrm{~d} t}-\omega_{s} \psi_{r q}+R_{r} i_{r d} \\
u_{r q} & =\frac{\mathrm{d} \psi_{r q}}{\mathrm{~d} t}+\omega_{s} \psi_{r d}+R_{r} i_{r q} \\
\psi_{s d} & =L_{s} i_{s d}+L_{m} i_{r d} \\
\psi_{s q} & =L_{s} i_{s q}+L_{m} i_{r q} \\
\psi_{r d} & =L_{r} i_{r d}+L_{m} i_{s d} \\
\psi_{r q} & =L_{r} i_{r q}+L_{m} i_{s q} \\
T_{e}-T_{m} & =J \frac{\mathrm{d} \omega_{m}}{\mathrm{~d} t}=\frac{J}{n_{p}} \frac{\mathrm{d} \omega_{r}}{\mathrm{~d} t} \\
T_{e} & =\frac{3 L_{m} n_{p}}{2 L_{s}}\left(\psi_{s d} i_{r q}-\psi_{s q} i_{r d}\right)
\end{aligned}
$$

where $u_{s d}, u_{s q}, i_{s d}, i_{s q}, \psi_{s d}$, and $\psi_{s q}$ are the d-q components of stator voltage, current, and flux, respectively; $u_{r d}, u_{r q}$, $i_{r d}, i_{r q}, \psi_{r d}$, and $\psi_{r q}$ are the d-q components of rotor voltage, current, and flux, respectively; $\omega_{1}, \omega_{s}, \omega_{r}$, and $\omega_{m}$ are synchronous, slip, rotor, and mechanical angular frequency, respectively; $L_{s}, L_{r}$, and $L_{m}$ are the stator, rotor, and mutual inductance respectively; $R_{r}$ and $R_{s}$ are the rotor and stator resistance, respectively; $T_{e}$ is electromagnetic torque; $J$ is generator rotational inertia; and $n_{p}$ is the number of pairs of poles.

\section{Control Strategy Description}

3.1. MPPT Control Strategy. Usually the maximum kinetic power captured from the wind by a wind turbine is expressed as follows [26]:

$$
P_{w \max }=\frac{1}{2} \rho \pi R_{w t} C_{\text {pmax }} V_{\text {wind }}^{3}
$$

where $\rho$ is air density, $R_{w t}$ is radius of wind turbine, $V_{\text {wind }}$ is wind speed, and $C_{\text {pmax }}$ is maximum power coefficient.

To capture the maximum wind power, the power coefficient $C_{p}$ should maintain maximum $C_{\text {pmax }}$ at any wind speed 

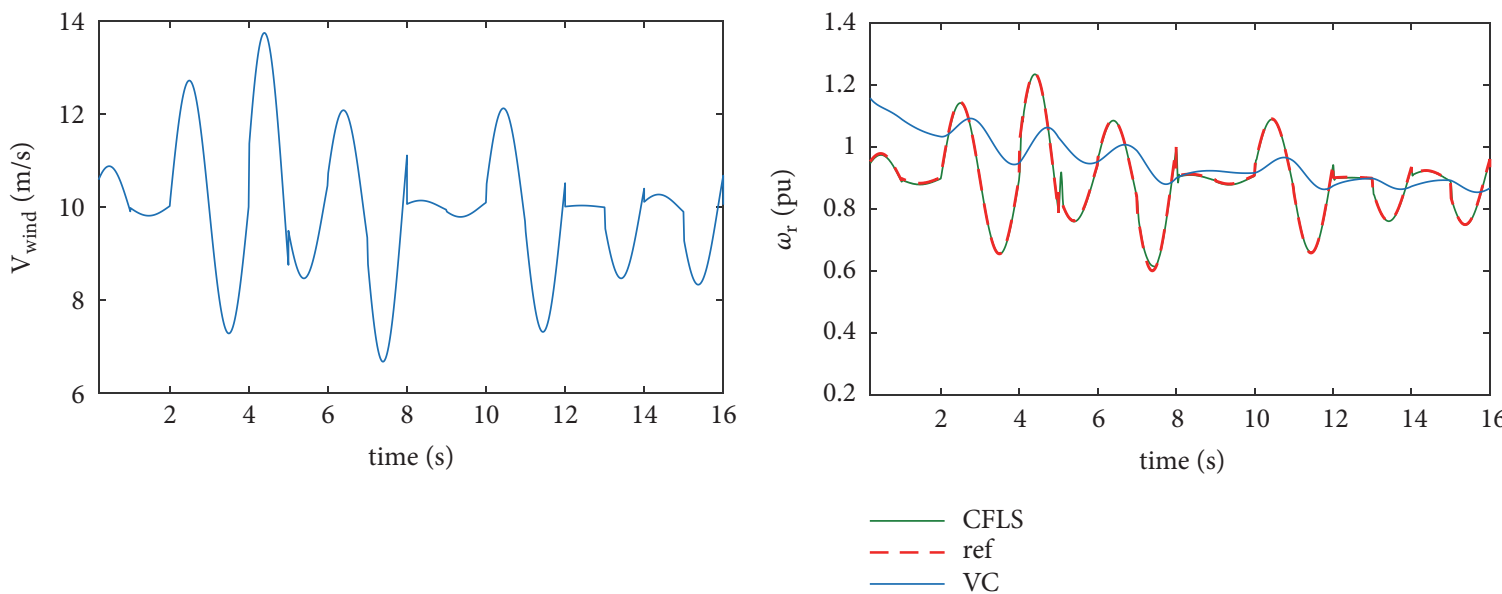

(a) Wind speed

(b) Rotor speed $\omega_{r}$
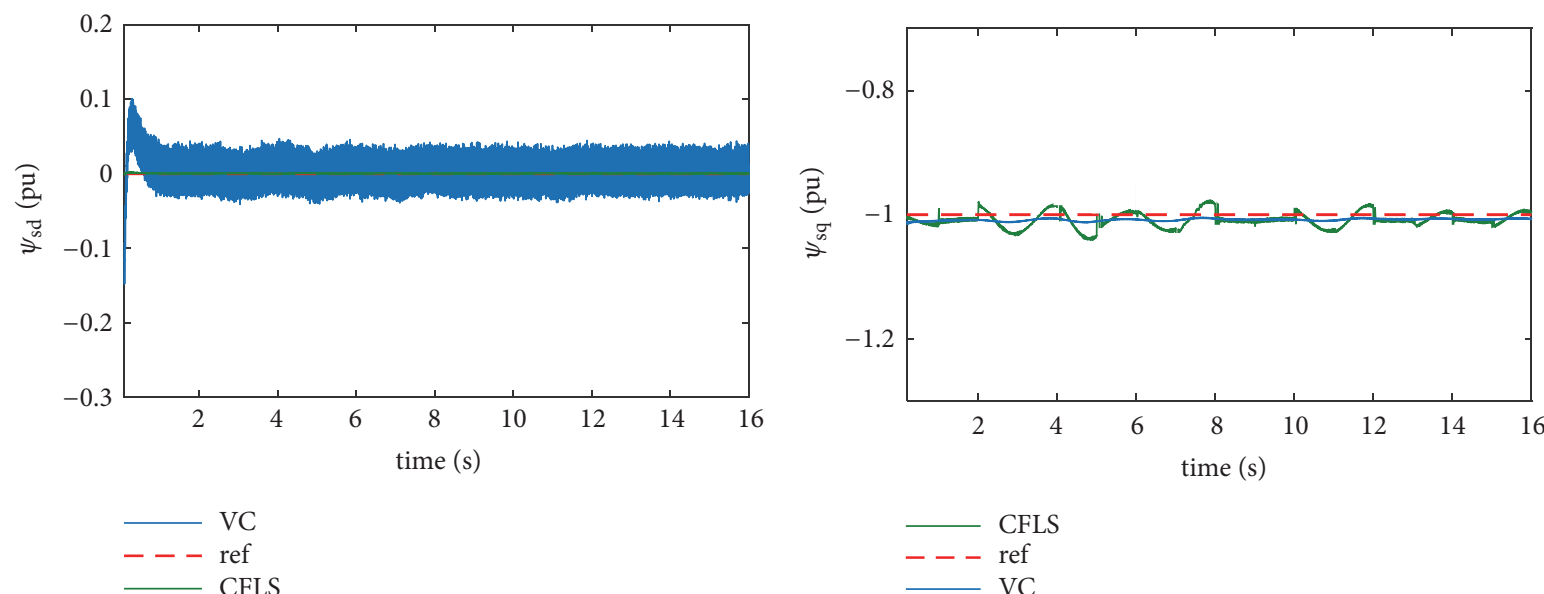

(c) $\psi_{s d}$

(d) $\psi_{s q}$
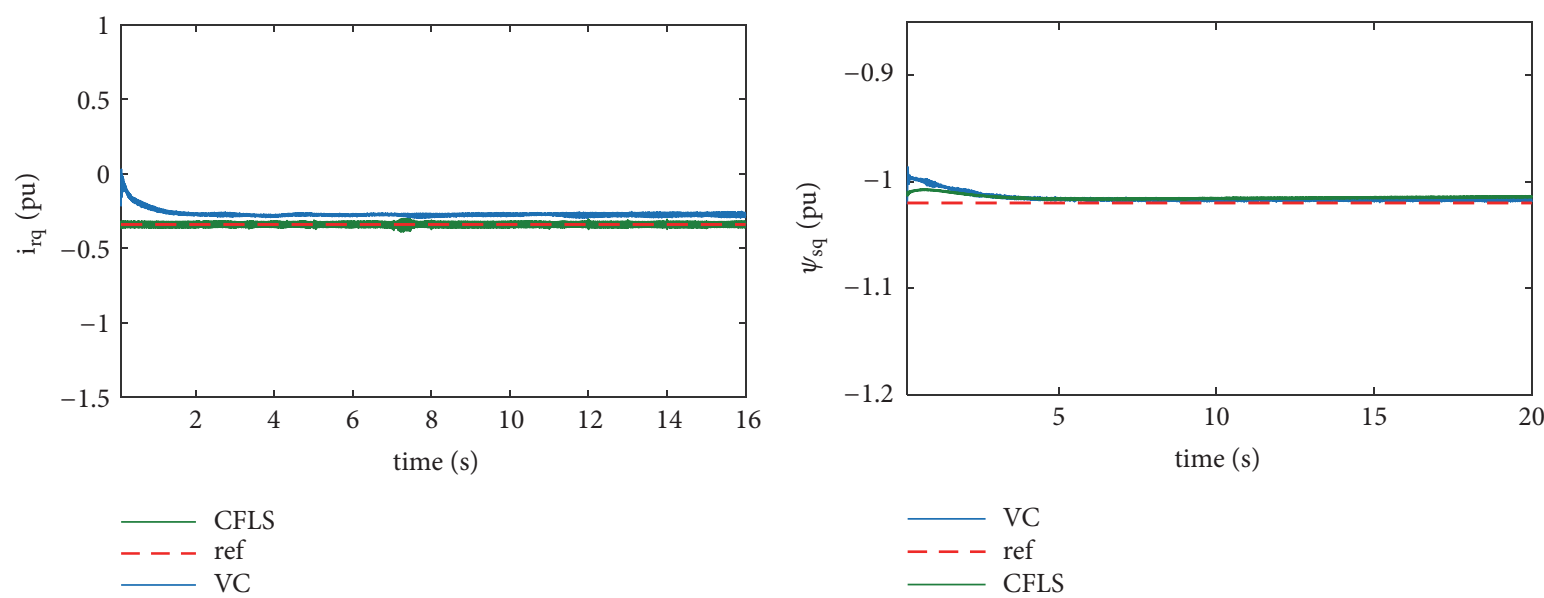

(e) $i_{r q}\left(x_{3}\right)$

(f) $i_{r d}$ under the CFLS

Figure 8: Performance response to the random-change wind speed. 


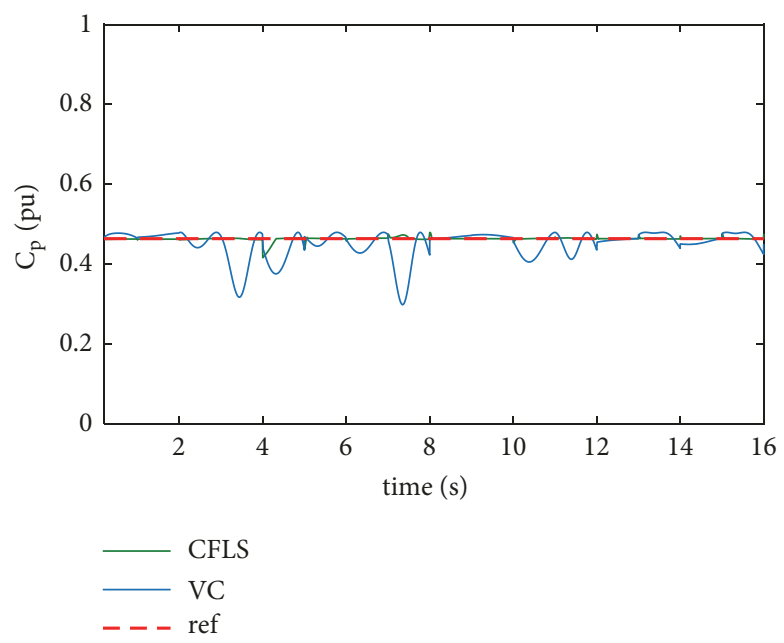

FIGURE 9: $C_{p}$ at the random-change wind speed.

within the operating range. Maximum $C_{p \max }$ is achieved by maintaining the tip speed ratio $\lambda$ equal to optimal value $\lambda_{\text {opt }}$ and the pitch angle $\beta$ at a fixed value.

$$
\begin{aligned}
C_{\text {pmax }}= & C_{p}\left(\lambda_{\text {opt }}\right) \\
= & 0.5176\left(\frac{116}{\lambda_{i}}-0.4 \beta-5\right) e^{-21 / \lambda_{i}} \\
& +0.0068 \lambda_{\text {opt }} \\
\frac{1}{\lambda_{i}}= & \frac{1}{\lambda_{\text {opt }}+0.08 \beta}-\frac{0.035}{\beta^{3}+1}
\end{aligned}
$$

The tip speed ratio $\lambda$ indicates the state of the wind wheel under different wind speeds, as

$$
\lambda=\frac{\omega_{r} R_{w t}}{K_{1} V_{\text {wind }}}
$$

When $\lambda$ is equal to $\lambda_{\text {opt }}$, the optimal reference $\omega_{r}^{*}$ is

$$
\omega_{r}^{*}=\frac{K_{1} \lambda_{o p t}}{R_{w t}} V_{w i n d}
$$

In this paper, the pitch angle is $\beta=0^{\circ}$, the optimal tip speed ratio is $\lambda_{o p t}=9.7$, and the maximum power coefficient is $C_{\text {pmax }}=0.4642 . P_{w t \max }$ is shown in the Figure 2.

3.2. CFLS of DFIG. From (1)-(3), the DFIG model can be derived in the form

$$
\begin{aligned}
& \dot{x}=f(x)+g(x) u \\
& y=h(x)
\end{aligned}
$$

where

$$
\begin{aligned}
& x=\left[\begin{array}{lllll}
x_{1} & x_{2} & x_{3} & x_{4} & x_{5}
\end{array}\right]^{T} \\
& =\left[\begin{array}{lllll}
\psi_{s d} & \psi_{s q} & i_{r d} & i_{r q} & \omega_{r}
\end{array}\right]^{T} \\
& u=\left[\begin{array}{llll}
u_{1} & u_{2} & u_{3} & u_{4}
\end{array}\right]^{T}=\left[\begin{array}{llll}
u_{s d} & u_{s q} & u_{r d} & u_{r q}
\end{array}\right]^{T} \\
& y=\left[\begin{array}{llll}
h_{1}(x) & h_{2}(x) & h_{3}(x) & h_{4}(x)
\end{array}\right]^{T} \\
& =\left[\begin{array}{llll}
x_{1} & x_{2} & x_{4} & x_{5}
\end{array}\right]^{T}=\left[\begin{array}{llll}
\psi_{s d} & \psi_{s q} & i_{r q} & \omega_{r}
\end{array}\right]^{T} \\
& f(x)=\left[\begin{array}{l}
f_{1}(x) \\
f_{2}(x) \\
f_{3}(x) \\
f_{4}(x) \\
f_{5}(x)
\end{array}\right] \\
& =\left[\begin{array}{c}
-\frac{R_{s}}{L_{s}} x_{1}+\omega_{1} x_{2}+\beta R_{s} x_{3} \\
-\omega_{1} x_{1}-\frac{R_{s}}{L_{s}} x_{2}+\beta R_{s} x_{4} \\
\frac{\beta R_{s}}{\alpha L_{s}} x_{1}-\frac{\beta}{\alpha} x_{2} x_{5}-\frac{R_{r}+\beta^{2} R_{s}}{\alpha} x_{3}+\omega_{s} x_{4} \\
\frac{\beta}{\alpha} x_{1} x_{5}+\frac{\beta R_{s}}{\alpha L_{s}} x_{2}-\omega_{s} x_{3}-\frac{R_{r}+\beta^{2} R_{s}}{\alpha} x_{4} \\
\frac{3 L_{m} n_{p}^{2}}{2 J L_{s}}\left(x_{1} x_{4}-x_{2} x_{3}\right)-\frac{n_{p}}{J} T_{m}
\end{array}\right]
\end{aligned}
$$




$$
\begin{aligned}
g(x)= & {\left[\begin{array}{l}
g_{1}(x) \\
g_{2}(x) \\
g_{3}(x) \\
g_{4}(x)
\end{array}\right]^{T} } \\
= & {\left[\begin{array}{cccc}
1 & 0 & 0 & 0 \\
0 & 1 & 0 & 0 \\
-\frac{\beta}{\alpha} & 0 & \frac{1}{\alpha} & 0 \\
0 & -\frac{\beta}{\alpha} & 0 & \frac{1}{\alpha} \\
0 & 0 & 0 & 0
\end{array}\right]\left\{\begin{array}{l}
\alpha=\frac{\left(L_{r} L_{s}-L_{m}^{2}\right)}{L_{s}} \\
\beta=\frac{L_{m}}{L_{s}}
\end{array}\right.}
\end{aligned}
$$

MIMO system is to differentiate the output $y_{i}$ of the system until the inputs $u_{j}$ appear, assuming that the corresponding relation degree $r_{i}$ is the smallest integer such that at least one of the inputs explicitly appears in [27]

$$
y_{i}^{\left(r_{i}\right)}=L_{f}^{r_{i}} h_{i}+\sum_{j=1}^{m} L_{g_{j}} L_{f}^{r_{i}-1} h_{i} u_{j}
$$

where $y_{i}^{\left(r_{i}\right)}$ denotes the $r_{i}$ th-order derivative of $y_{i}$.

In (8), $x$ is 5 dimensional state phase quantity, $f_{i}(x)(i=$ $1,2, \ldots, 5)$ is $5 d$ smooth vector field, and $g_{i}(x)(i=1,2,3,4)$ is $4 d$ smooth vector field. Each output $y_{i}$ has a $r_{i}$, and by calculating that is $1,1,1$ and 2 . The system relation degree is $r=1+1+1+2=5=n$; therefore, the system

This is a multi-input multioutput (MIMO) system. An approach to obtain the inputCoutput linearization of the

has no nontrivial zero dynamics, which can be linearized by feedback linearization. According to (10) and $r_{i}$ of each output $y_{i}$, the Lie Derivative of $h$ with along $f$ and the Lie Derivative of $L_{f} h(x)$ with along $g(x)$ are obtained, and they are

$$
\left[\begin{array}{c}
\dot{y}_{1} \\
\dot{y}_{2} \\
\dot{y}_{3} \\
\ddot{y}_{4}
\end{array}\right]=\left[\begin{array}{c}
L_{f} h_{1}(x) \\
L_{f} h_{2}(x) \\
L_{f} h_{3}(x) \\
L_{f}^{2} h_{4}(x)
\end{array}\right]+\left[\begin{array}{cccc}
L_{g_{1}} L_{f}^{0} h_{1}(x) & L_{g_{2}} L_{f}^{0} h_{1}(x) & L_{g_{3}} L_{f}^{0} h_{1}(x) & L_{g_{4}} L_{f}^{0} h_{1}(x) \\
L_{g_{1}} L_{f}^{0} h_{2}(x) & L_{g_{2}} L_{f}^{0} h_{2}(x) & L_{g-3} L_{f}^{0} h_{2}(x) & L_{g_{4}} L_{f}^{0} h_{2}(x) \\
L_{g_{1}} L_{f}^{0} h_{3}(x) & L_{g_{2}} L_{f}^{0} h_{3}(x) & L_{g_{3}} L_{f}^{0} h_{3}(x) & L_{g_{4}} L_{f}^{0} h_{3}(x) \\
L_{g_{1}} L_{f}^{1} h_{4}(x) & L_{g_{2}} L_{f}^{1} h_{4}(x) & L_{g_{3}} L_{f}^{1} h_{4}(x) & L_{g_{4}} L_{f}^{1} h_{4}(x)
\end{array}\right]\left[\begin{array}{l}
u_{1} \\
u_{2} \\
u_{3} \\
u_{4}
\end{array}\right]
$$

According to (8) and (11), the system can be described in the following matrix form:

$$
\left[\begin{array}{llll}
\dot{y}_{1} & \dot{y}_{2} & \dot{y}_{3} & \ddot{y}_{4}
\end{array}\right]^{T}=A(x)+E(x) u
$$

where

$$
\begin{gathered}
A(x) \\
=\left[\begin{array}{c}
-\frac{R_{s}}{L_{s}} x_{1}+\omega_{1} x_{2}+\beta R_{s} x_{3} \\
-\omega_{1} x_{1}-\frac{R_{s}}{L_{s}} x_{2}+\beta R_{s} x_{4} \\
\xi\left[\left(-\frac{R_{s}}{L_{s}}-\frac{R_{r}+\beta^{2} R_{s}}{\alpha}\right) x_{1} x_{4}+\left(\omega_{1}-\omega_{s}\right)\left(x_{2} x_{4}+x_{1} x_{3}\right)\right. \\
\frac{\beta}{\alpha} x_{1} x_{5}+\frac{\beta R_{s}}{\alpha L_{s}} x_{2}-\omega_{s} x_{3}-\frac{R_{r}+\beta^{2} R_{s}}{\alpha} x_{4} \\
\left.+\left(\frac{R_{s}}{L_{s}}+\frac{R_{r}+\beta^{2} R_{s}}{\alpha}\right) x_{2} x_{3}+\frac{\beta}{\alpha} x_{5}\left(x_{1}^{2}+x_{2}^{2}\right)\right]
\end{array}\right]
\end{gathered}
$$

$$
\begin{aligned}
& =\left[\begin{array}{cccc}
1 & 0 & 0 & 0 \\
0 & 1 & 0 & 0 \\
0 & -\frac{\beta}{\alpha} & 0 & \frac{1}{\alpha} \\
2 \xi\left(x_{4}+\frac{\beta}{\alpha} x_{2}\right) & -2 \xi\left(x_{3}+\frac{\beta}{\alpha} x_{1}\right) & -2 \xi\left(\frac{1}{\alpha} x_{2}\right) & 2 \xi\left(\frac{1}{\alpha} x_{1}\right)
\end{array}\right] \\
& \xi=\frac{3 L_{m} n_{p}^{2}}{2 J L_{s}}
\end{aligned}
$$

There is $\operatorname{det}(E(x))=2 \xi x_{2} / \alpha^{2} \neq 0$, so the inverse matrix $E(x)^{-1}$ exists. A new input variable is defined for input-output feedback linearization, as $v=\left[\begin{array}{llll}v_{1} & v_{2} & v_{3} & v_{4}\end{array}\right]$. The conversion relation between the original input variable and the new input variable is as follows:

$$
u=E(x)^{-1}(-A(x)+v)
$$

where $\left[\begin{array}{llll}\dot{y}_{1} & \dot{y}_{2} & \dot{y}_{3} & \ddot{y}_{4}\end{array}\right]^{T}=\left[\begin{array}{llll}v_{1} & v_{2} & v_{3} & v_{4}\end{array}\right]^{T}$. Thus, the inputoutput mapping of (8) can be simplified as (14), which realizes the linear decoupling between the system output and input variables. According to the MTTP control strategy, and the output is stabilized at $\sigma^{*}=\left[\begin{array}{llll}\psi_{s d}^{*} & \psi_{s q}^{*} & i_{r q}^{*} & \omega_{r}^{*}\end{array}\right]^{T}$, where $\psi_{s d}^{*} \psi_{s q}^{*} i_{r q}^{*} \omega_{r}^{*}$ are the MPP reference value of the system. Through variable substitution $e=\sigma^{*}-y$ the equilibrium 


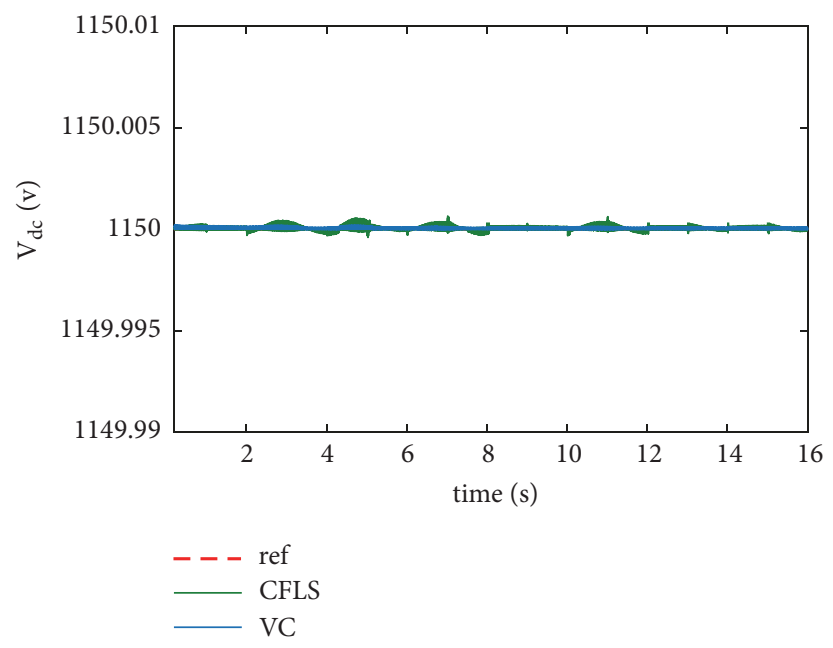

Figure 10: $V_{d c}$ at the random-change wind speed.

point is moved to the origin, and the input variable can be redesigned into (14)

$$
\begin{aligned}
{\left[\begin{array}{c}
v_{1} \\
v_{2} \\
v_{3} \\
v_{4}
\end{array}\right]=\left[\begin{array}{l}
\dot{\psi}_{s d}^{*}-k_{p 1} e_{1}-k_{i 1} \int e_{1} d t \\
\dot{\psi}_{s q}^{*}-k_{p 2} e_{2}-k_{i 2} \int e_{2} d t \\
i_{r q}^{*}-k_{p 3} e_{3}-k_{i 3} \int e_{3} d t \\
\ddot{\omega}_{r}^{*}-k_{p 4} e_{4}-k_{i 4} \int e_{4} d t
\end{array}\right] } \\
\ddot{e}_{i}+k_{p i} \dot{e}_{i}+k_{i i} e_{i}=0
\end{aligned}
$$

In the controller design we can choice the parameters $k_{p i}$ and $k_{i i}(i=1,2,3,4)$ in (15) and (16) to ensure the convergence and stability of the $e_{i}(i=1,2,3,4)$. Now we have derived that the partial states $x_{1} x_{2} x_{3} x_{4}$ track the setting reference points.

Therefore, from the above analysis, the whole control scheme is shown in Figure 3.

3.3. Reference Points of Controller. The rotor flux and stator current are the control targets; the method determined in this paper is that, when a stator-oriented flux frame is adopted with its vector direction aligned with the q-axis, from (2), the stator flux reference value $\left(\psi_{s}^{*}\right)$ and its d-q components are given by

$$
\begin{aligned}
& \psi_{s d}^{*}=0 \\
& \psi_{s q}^{*}=\psi_{s}^{*}=-\frac{V_{S}}{\omega_{1}}=-1
\end{aligned}
$$

where $V_{s}$ is generator rated voltage amplitude, $\omega_{1}$ is synchronous speed. In this paper, $V_{s}=1.0 \mathrm{pu}, \omega_{1}=1.0 \mathrm{pu}$. Substituting (17) into (2), the rotor current are obtained:

$$
i_{r q}^{*}=-\frac{\psi_{s}^{*}}{L_{m}}=-0.34
$$

3.4. Stability Analysis of State Variable $x_{3}$. From the error equation (16), we obtain that the partial states $x_{1} x_{2} x_{4} x_{5}$ are bounded are converge to the reference point. Next we will analyze the boundedness of the state $x_{3}$. From (8), the equation about $x_{3}$ is extracted

$$
\begin{aligned}
\dot{x}_{3}= & \frac{\beta R_{s}}{\alpha L_{s}} x_{1}-\frac{\beta}{\alpha} x_{2} x_{5}-\frac{R_{r}+\beta^{2} R_{s}}{\alpha} x_{3}+\omega_{s} x_{4}-\frac{\beta}{\alpha} u_{s d} \\
& +\frac{1}{\alpha} u_{r d}
\end{aligned}
$$

Substituting (14) into (19), that can be derived as

$$
\begin{aligned}
\dot{x}_{3} & =\left(\frac{3 \beta^{2} R_{s}-R_{r}}{2 \alpha}+\frac{2 R_{s}}{2 L_{s}}\right. \\
& \left.+\frac{2 \omega_{1} x_{1}-\left(\beta R_{s}+1\right) x_{4}+v_{2}}{x_{2}}-\frac{x_{5} x_{1}}{2 x_{2}}\right) x_{3} \\
& -\frac{\beta x_{2} x_{5}}{2 \alpha}+\left(\frac{R_{s}}{L_{s}}+\frac{R_{r}+\beta^{2} R_{s}}{\alpha}\right) \frac{x_{1} x_{4}}{2 x_{2}}-\frac{x_{5} x_{4}}{2} \\
& -\frac{\beta x_{5} x_{1}^{2}}{2 \alpha x_{2}}+\frac{x_{4} v_{1}+x_{1} v_{3}}{x_{2}}-\frac{1}{2 \xi x_{2}} v_{4}
\end{aligned}
$$

From (15), the states $x_{1} x_{2} x_{4} x_{5}$ are convergent to $\psi_{s d}^{*} \psi_{s q}^{*} i_{r q}^{*} \omega_{r}^{*}$, and further from (17), (18), and (7) know that their values are $0-1-0.340 .09 V_{\text {wind }}$, so that dynamics (20) can be approximated as

$$
\dot{x}_{3}=-0.0588 x_{3}+0.14355 V_{\text {wind }}+0.0243 \ddot{V}_{\text {wind }}
$$

In this paper, the rated wind speed of wind turbine is $V_{\text {wind nom }}=13 \mathrm{~m} / \mathrm{s}$, and the variable wind speed range is focus on 6-14 m/s. And the high frequency components in the wind speed measurement $V_{\text {wind }}$ may cause undesired noise; therefore the measured wind speed is passed through lowpass filter to attenuate its effect [28]. It is assumed that the 


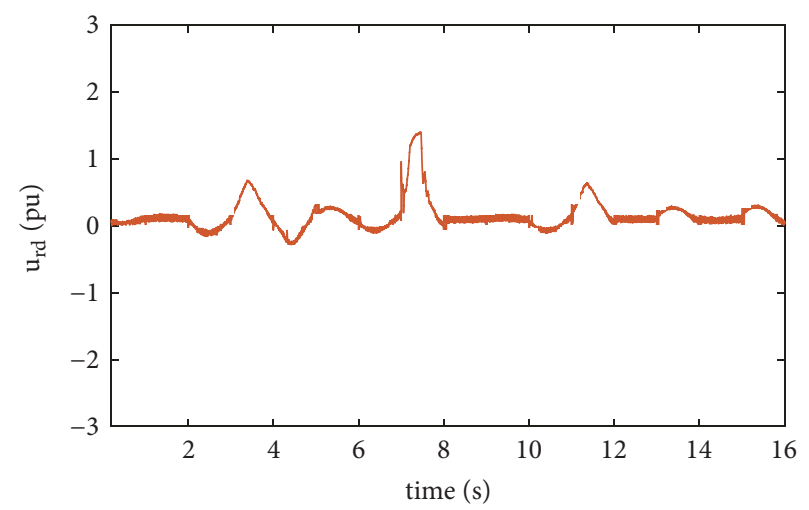

(a) $u_{r d}$ under the CFLS

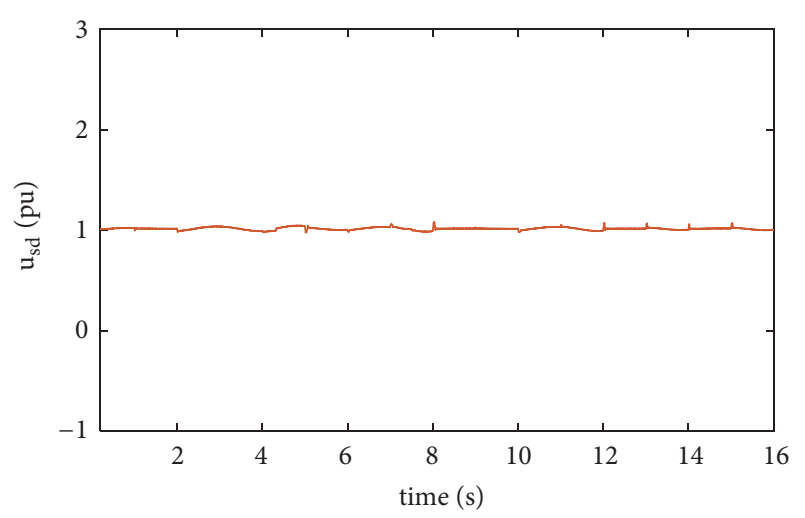

(c) $u_{s d}$ under the CFLS

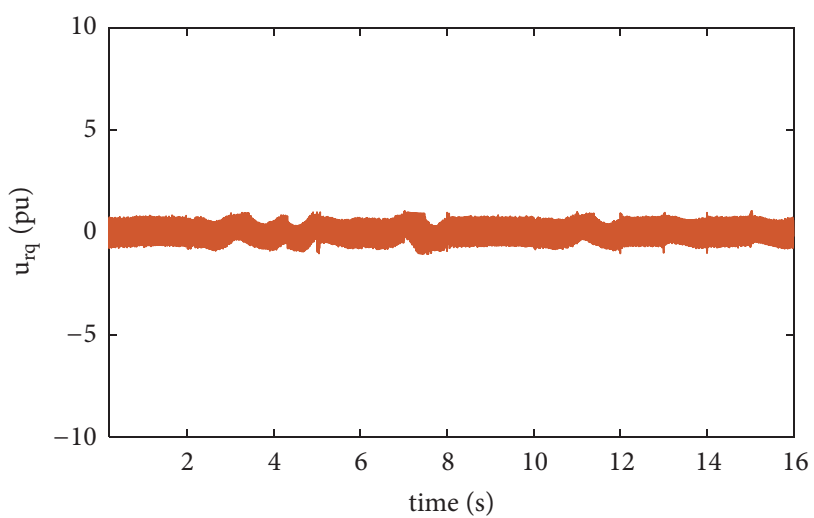

(b) $u_{r q}$ under the CFLS

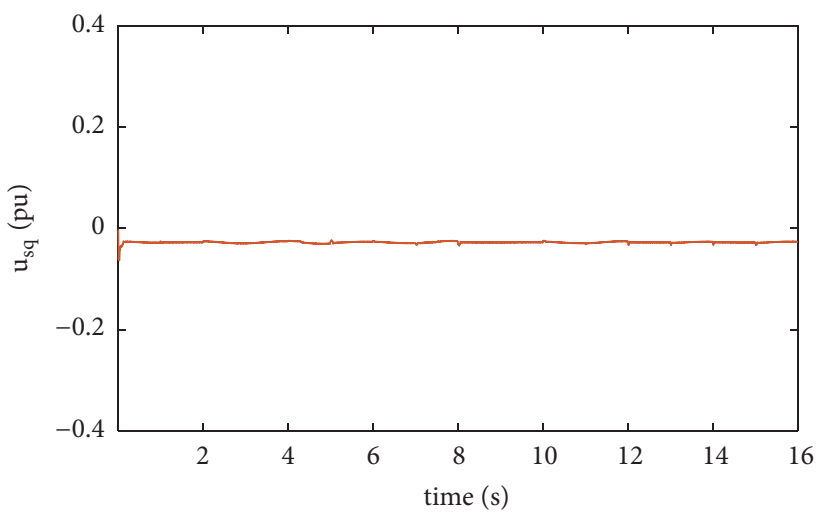

(d) $u_{s q}$ under the CFLS

FIGURE 11: The output control signals response to the random-change wind speed.

magnitude of its derivative $\left|\ddot{V}_{\text {wind }}\right|$ is bounded as $\left|\ddot{V}_{\text {wind }}\right| \leq 5$; it becomes

$$
\dot{x}_{3}=-0.0588 x_{3}+M \quad 0.7385 \leq M \leq 2.1215
$$

The above can be known, the state variable $x_{3}\left(i_{r d}\right)$ is bounded, when $t \longrightarrow \infty$.

\section{Simulation Results}

In this section, simulation results are carried out in MATLAB/SIMULINK, to verify the coordinated optimal control performance in a wide range operating conditions. There are two tests performed: case one shows the accuracy of CFLS compare with the VC under the ramp-change wind and case two is the system that operates at random-change wind to show the tracking speed of controller. The DFIG system parameters in the following simulation are listed in Appendix A.

4.1. Ramp-Change Wind. Figures 4-7 shows the performance of a DFIG in DC-grid controlled by the VC and CFLS under the ramp-change wind. The wind speed condition is depicted in Figure 4(a). The wind speed rises from $7 \mathrm{~m} / \mathrm{s}$ to $14 \mathrm{~m} / \mathrm{s}$ and then remains $14 \mathrm{~m} / \mathrm{s}$. It can be seen from Figure 4(b) that the optimal reference rotor speed $\omega_{r}^{*}$ is well tracked by the CFLS, while the response of the VC with larger overshoots is slower. Figures 4(c), 4(e), and 4(f) show that the tracking references performance of VC and CFLS and the tracking accuracy of CFLS are better than that of VC. The state variable $x_{3}\left(i_{r d}\right)$ is shown in Figure 4(d), as it keep stable in both VC and CFLS under ramp-change wind.

As shown in Figure 5, the CFLS can well capture the maximum power coefficient $C_{\text {pmax }}$ value, but the VC needs long time to catch $C_{\text {pmax }}$. It means that the wind turbine maintains the maximum output power under the proposed control strategy.

Figure 6 shows the system output DC-voltage $V_{d c}$ that connected to a stable DC-grid. It can be seen that the DC voltage remains stable under the control of CFLS and VC, when the wind ramp changes.

The rotor currents and voltages $\left(i_{r a b c}, u_{r a b c}\right)$, and the stator currents and voltages $\left(i_{s a b c}, u_{s a b c}\right)$ can be seen that the DFIG is operated at the rated value while under the CFLS in Figure 7. $i_{s a b c}$ and $u_{s a b c}$ are sine wave with frequency of $60 \mathrm{~Hz}$, and their amplitudes are $1.0 \mathrm{pu}$ and $0.8 \mathrm{pu} . i_{\text {rabc }}$ is sine wave with amplitude of $0.85 \mathrm{pu} . u_{\mathrm{rabc}}$ is the RSC output pulse wave, and its amplitude is $0.7 \mathrm{pu}$.

4.2. Random-Change Wind. The performance of a DC-based DFIG system controlled by the VC and CFLS under randomchange wind is shown in Figures 8-11. The wind speed 
condition is depicted in Figure 8(a), which fluctuates between $6.8 \mathrm{~m} / \mathrm{s}$ and $13.4 \mathrm{~m} / \mathrm{s}$. As shown in Figures $8(\mathrm{~b}), 8(\mathrm{c}), 8(\mathrm{~d})$, and $8(\mathrm{e})$, the tracking speed and accuracy of CFLS are obviously better than VC when the wind speed is time-varying. The state variable $x_{3}\left(i_{r d}\right)$ in the CFLS is shown in Figure $8(\mathrm{f})$, as it can stay mostly stable under the influence of random-change wind.

When the wind speed changes at any time, the power coefficient $C_{p}$ should be kept at the maximum value in order to extract the maximum wind power. As shown in Figure 9, the maximum power coefficient $C_{\text {pmax }}$ can be well captured by the CFLS. However, the change of the wind speed will affect the maximum power coefficient $C_{\text {pmax }}$ obtained by the VC strategy. This means that the CFLS maximum power tracking performance is much better than $\mathrm{VC}$ in a wide range operating conditions.

System output DC-voltage $V_{d c}$ connected to a stable DCgrid in the random-change wind speed is shown in Figure 10; it remains stable under the control of CFLS and VC.

The output control signals $u_{r d} u_{r q} u_{s d} u_{s q}$ of controllers are listed in Figure 11. Under the CFLS, because of the rotor speed $\omega_{r}$ tracking the optimal reference rotor speed $\omega_{r}^{*}$ that fluctuates follow the random-change wind, so the rotor side output signals $u_{r d} u_{r q}$ are fluctuated near the working point. But the stator side output signals $u_{s d} u_{s q}$ less fluctuant and operate steadily at working point. This shows that the proposed control strategy achieves the complete decoupling of DC-based DFIG system and that the stator side and rotor side have each performs its own functions, and coordinate the work.

\section{Conclusion}

From the simulation results and analysis, the following conclusions may be drawn out:

(1) A coordinated feedback linearization strategy is applied to achieve the complete decoupling and linearization for the DFIG with DC-based converter system.

(2) This paper gives up the traditional indirect dual-loop control method of power and current and selects stator flux $\left(\psi_{s d} \psi_{s q}\right)$, rotor speed $\left(\omega_{r}\right)$, and rotor current $\left(i_{r q}\right)$ as state variables. A direct single-loop coordinated control method is implemented, which achieves the division cooperation between stator side and rotor side, and enhances the robustness of the system.

(3) The maximum power point tracking performance of the proposed control strategy is better than traditional VC. The CFLS kept power coefficient $\left(C_{p}\right)$ at its maximum, to make DFIG operate at the maximum power point (MPP).

In further study, this experiment will be extended to verify the effectiveness of the system in case of failure.

\section{Appendix}

A.

A.1. DFIG Parameters [29]. $P_{\text {rated }}=1.5 \mathrm{MW}, f_{\text {nom }}=60 \mathrm{~Hz}$, $v_{\text {s`nom }}=1.0 \mathrm{pu}, \omega_{\mathrm{s}}=1.0 \mathrm{pu}, R_{\mathrm{s}}=0.00706 \mathrm{pu}$,

$R_{r}=0.005 \mathrm{pu}, L_{l s}=0.171 \mathrm{pu}, L_{m s}=2.9 \mathrm{pu}, n_{p}=3$.
A.2. Wind Turbine Parameters. $\rho=1.225 \mathrm{~kg} / \mathrm{m}^{3}, R_{w t}=$ $40 \mathrm{~m}^{2}, k_{1}=3.711, H=5.04 \mathrm{~S}, V_{\text {windnom }}=13 \mathrm{~m} / \mathrm{s}$.

\section{A.3. VC Parameters [11]. RSC:}

Outer-loop: $k_{p p}=4, k_{p i}=0.1$;

Inner-loop: $k_{r p}=0.496, k_{r i}=0.0128$.

SSC:

$$
\begin{aligned}
& \text { Outer-loop: } k_{u p}=4, k_{u i}=0.1 \\
& \text { Inner-loop: } k_{s p}=0.496, k_{s i}=0.0128 .
\end{aligned}
$$

\section{Data Availability}

The data used to support the findings of this study are available from the corresponding author upon request.

\section{Conflicts of Interest}

The authors declare that they have no conflicts of interest.

\section{Acknowledgments}

This work was supported by National Natural Science Foundation of China (61473170).

\section{References}

[1] F. Akel, T. Ghennam, E. M. Berkouk, and M. Laour, "An improved sensorless decoupled power control scheme of grid connected variable speed wind turbine generator," Energy Conversion and Management, vol. 78, pp. 584-594, 2014.

[2] X. She, A. Q. Huang, S. Lukic, and M. E. Baran, "On integration of solid-state transformer with zonal DC microgrid," IEEE Transactions on Smart Grid, vol. 3, no. 2, pp. 975-985, 2012.

[3] W. Chen, A. Q. Huang, C. Li, G. Wang, and W. Gu, "Analysis and comparison of medium voltage high power DC/DC converters for offshore wind energy systems," IEEE Transactions on Power Electronics, vol. 28, no. 4, pp. 2014-2023, 2013.

[4] M. F. Iacchetti, G. D. Marques, and R. Perini, "A scheme for the power control in a DFIG connected to a DC bus via a diode rectifier," IEEE Transactions on Power Electronics, vol. 30, no. 3, pp. 1286-1296, 2015.

[5] G. D. Marques and M. F. Iacchetti, "Inner control method and frequency regulation of a DFIG connected to a dc link," IEEE Transactions on Energy Conversion, vol. 29, no. 2, pp. 435-444, 2014.

[6] M. F. Iacchetti, G. D. Marques, and R. Perini, "Torque Ripple Reduction in a DFIG-DC System by Resonant Current Controllers," IEEE Transactions on Power Electronics, vol. 30, no. 8, pp. 4244-4254, 2015.

[7] G. D. Marques and M. F. Iacchetti, "A Self-Sensing StatorCurrent-Based Control System of a DFIG Connected to a DCLink," IEEE Transactions on Industrial Electronics, vol. 62, no. 10, pp. 6140-6150, 2015.

[8] R. Zhu, Z. Chen, and X. Wu, "Diode rectifier bridge-based structure for DFIG-based wind turbine," in Proceedings of the IEEE Applied Power Electronics Conference and Exposition (APEC '15), pp. 1290-1295, Charlotte, NC, USA, March 2015. 
[9] H. Nian and X. Yi, "Coordinated control strategy for doublyfed induction generator with DC connection topology," IET Renewable Power Generation, vol. 9, no. 7, pp. 747-756, 2015.

[10] S. Yan, A. Zhang, H. Zhang, J. Wang, and B. Cai, "An Optimum Design for a DC-Based DFIG System by Regulating Gearbox Ratio," IEEE Transactions on Energy Conversion, vol. 33, no. 1, pp. 223-231, 2018.

[11] S. Yan, A. Zhang, H. Zhang, and J. Wang, "Control scheme for DFIG converter system based on DC-transmission," IET Electric Power Applications, vol. 11, no. 8, pp. 1441-1448, 2017.

[12] S. Yan, A. Zhang, H. Zhang, J. Wang, and B. Cai, “Transient stability enhancement of DC-connected DFIG and its converter system using fault protective device," Journal of Modern Power Systems and Clean Energy, vol. 5, no. 6, pp. 887-896, 2017.

[13] S. Yan, A. Zhang, H. Zhang, J. Wang, and B. Cai, "Optimized and coordinated model predictive control scheme for DFIGs with DC-based converter system," Journal of Modern Power Systems and Clean Energy, vol. 5, no. 4, pp. 620-630, 2017.

[14] W. Qiao, L. Qu, and R. G. Harley, "Control of IPM synchronous generator for maximum wind power generation considering magnetic saturation," IEEE Transactions on Industry Applications, vol. 45, no. 3, pp. 1095-1105, 2009.

[15] N. Reddy Naguru, A. Karthikeyan, C. Nagamani, and V. Sravan Kumar, "Comparative study of power control of DFIG using PI control and feedback linearization control," in Proceedings of the International Conference on Advances in Power Conversion and Energy Technologies (APCET '12), pp. 1-6, August 2012.

[16] L. Jiang and Q. Wu, "Nonlinear adaptive control via slidingmode state and perturbation observer," IEEE Proceedings Control Theory and Applications, vol. 149, no. 4, pp. 269-277, 2002.

[17] Z. Zhang, Y. Wu, and J. Huang, "Differential-flatness-based finite-time anti-swing control of underactuated crane systems," Nonlinear Dynamics, vol. 87, no. 3, pp. 1749-1761, 2017.

[18] L. Gao and D. Wang, "Input-to-state stability and integral inputto-state stability for impulsive switched systems with time-delay under asynchronous switching," Nonlinear Analysis: Hybrid Systems, vol. 20, pp. 55-71, 2016.

[19] X. Yan, X. Song, and X. Wang, "Global output-feedback stabilization for nonlinear time-delay systems with unknown control coefficients," International Journal of Control, Automation, and Systems, vol. 16, no. 4, pp. 1550-1557, 2018.

[20] X. Xie, N. Duan, and C. Zhao, "A combined homogeneous domination and sign function approach to output-feedback stabilization of stochastic high-order nonlinear systems," IEEE Transactions on Automatic Control, vol. 59, no. 5, pp. 1303-1309, 2014.

[21] Y. Wu, J. Yu, and Y. Zhao, "Output feedback regulation control for a class of cascade nonlinear systems and its application to fan speed control," Nonlinear Analysis: Real World Applications, vol. 13, no. 3, pp. 1278-1291, 2012.

[22] X. Lin, K. S. Xiahou, Y. Liu, Y. B. Zhang, and Q. H. Wu, "Maximum power point tracking of DFIG-WT using feedback linearization control based current regulators," in Proceedings of the IEEE Innovative Smart Grid Technologies - Asia (ISGT-Asia '16), pp. 718-723, Melbourne, Australia, November 2016.

[23] B. Yang, L. Jiang, L. Wang, W. Yao, and Q. Wu, "Nonlinear maximum power point tracking control and modal analysis of DFIG based wind turbine," International Journal of Electrical Power \& Energy Systems, vol. 74, pp. 429-436, 2016.

[24] R. Cardenas, R. Pena, S. Alepuz, and G. Asher, "Overview of control systems for the operation of DFIGs in wind energy applications," IEEE Transactions on Industrial Electronics, vol. 60, no. 7, pp. 2776-2798, 2013.

[25] M. Tazil, V. Kumar, R. C. Bansal et al., "Three-phase doubly fed induction generators: an overview," IET Electric Power Applications, vol. 4, no. 2, pp. 75-89, 2010.

[26] W. Qiao, "Dynamic modeling and control of doubly fed induction generators driven by wind turbines," in Proceedings of the IEEE/PES Power Systems Conference and Exposition (PSCE '09), pp. 1-8, March 2009.

[27] H. K. Khalil, Nonlinear Systems, 3rd edition, 2002.

[28] W. Qiao, W. Zhou, J. M. Aller, and R. G. Harley, "Wind speed estimation based sensorless output maximization control for a wind turbine driving a DFIG," IEEE Transactions on Power Electronics, vol. 23, no. 3, pp. 1156-1169, 2008.

[29] N. W. Miller et al., "Dynamic modeling of GE 1.5 and 3.6 MW wind turbine-generators for stability simulations," Power Engineering Society General Meeting IEEE, vol. 3, pp. 1977-1983, 2004. 


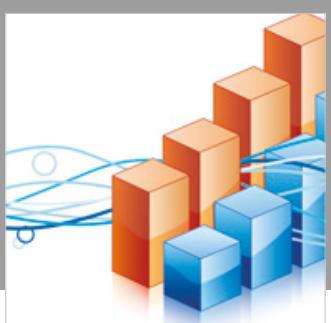

Advances in

Operations Research

\section{-n-m}
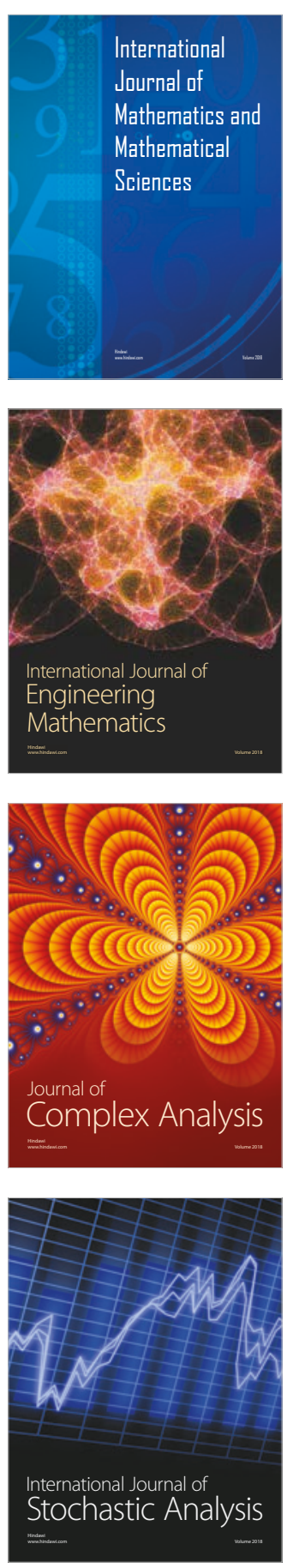
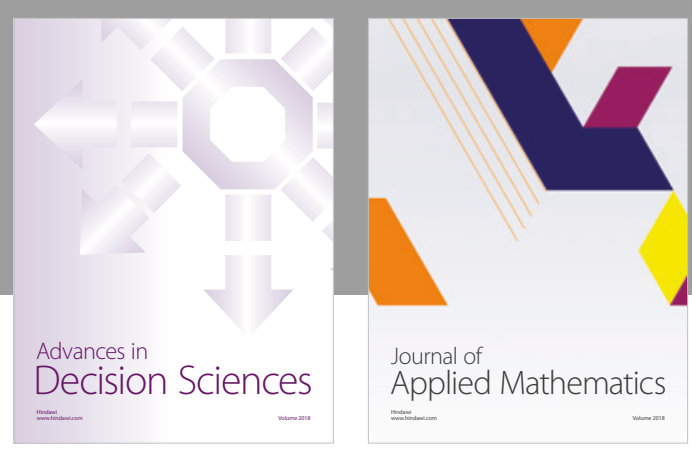

Journal of

Applied Mathematics
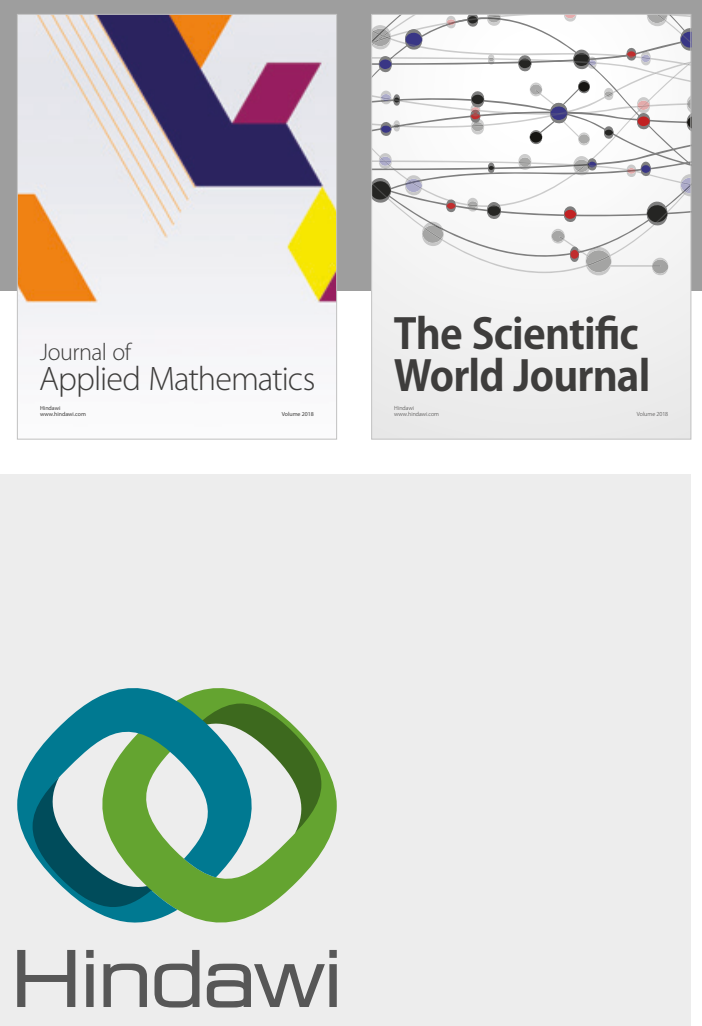

Submit your manuscripts at

www.hindawi.com

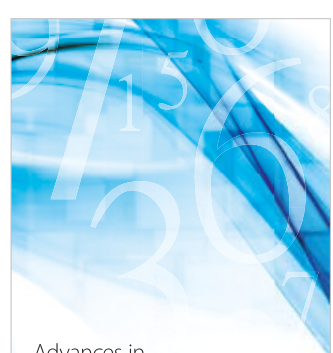

Advances in
Numerical Analysis
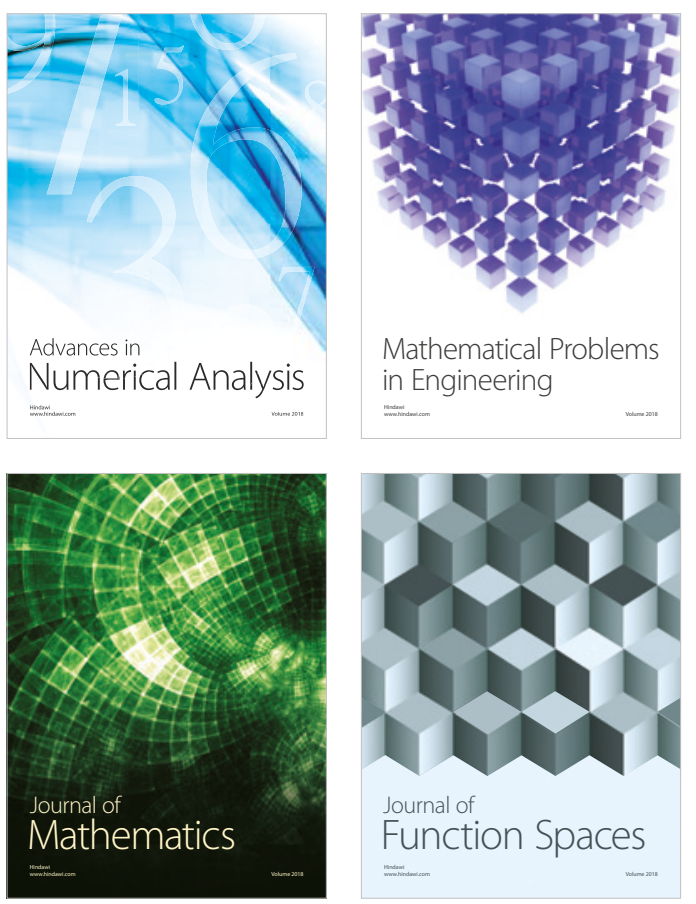

Mathematical Problems in Engineering

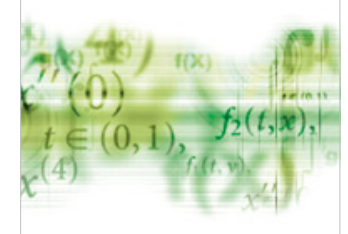

International Journal of

Differential Equations

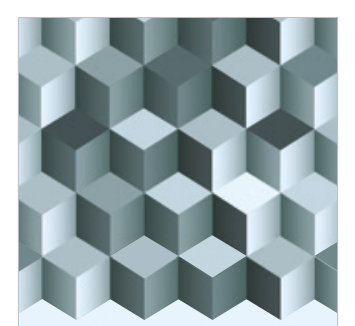

Journal of

Function Spaces

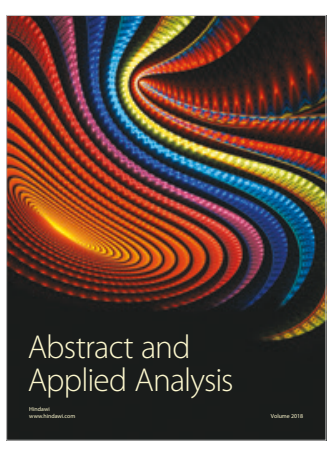

The Scientific

World Journal

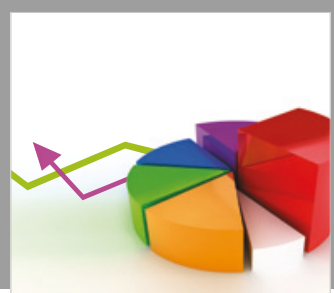

Journal of

Probability and Statistics
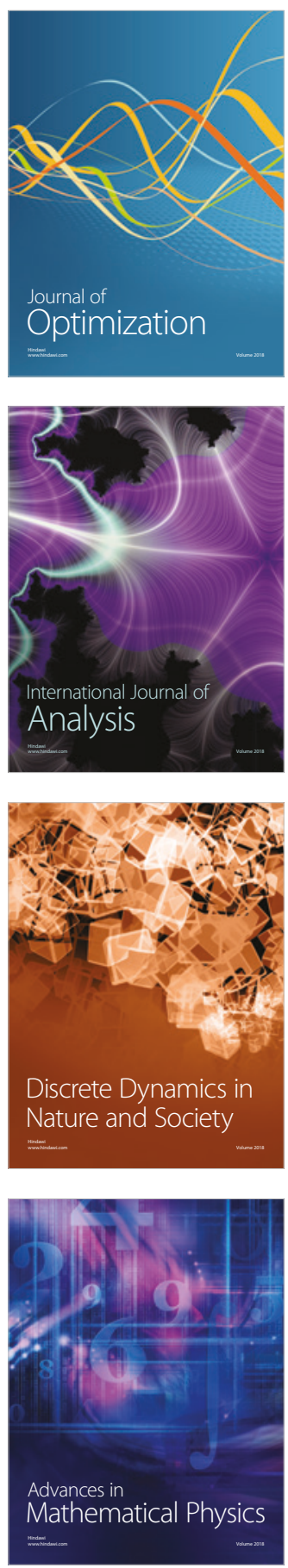